\title{
Provoked vestibulodynia: current perspectives
}

This article was published in the following Dove Press journal:

International Journal of Women's Health

II September 2017

Number of times this article has been viewed

\author{
Helen Henzell ${ }^{1,2}$ \\ Karen Berzins ${ }^{1,3}$ \\ Jennifer P Langford ${ }^{4}$ \\ 'Melbourne Sexual Health Centre, \\ Carlton, ${ }^{2}$ Action Centre, Family \\ Planning Victoria, Melbourne, \\ ${ }^{3}$ Dermatology/Vulval Conditions \\ Clinic, Mercy Hospital for \\ Women, Heidelberg, ${ }^{4}$ Clifton \\ Hill Physiotherapy, Clifton Hill, \\ VIC, Australia
}

\begin{abstract}
Provoked vestibulodynia (PVD) refers to vulvar pain of at least 3 months duration, localized to the vestibule, provoked by touch and sexual activity and occurring in the absence of a clear identifiable cause. The clinical spectrum ranges from mild with distressing discomfort through to severe and disabling pain. Current understanding is that PVD is one of many chronic pain conditions characterized by sensitization of peripheral and central nociceptive pathways, with pain arising due to dysfunctional neuronal activity in the absence of painful stimuli. Pathophysiology is not well understood but is likely a complex interplay of environmental, genetic, psychological and immune factors. Care is multidisciplinary and follows general principles of chronic pain management with the addition of specific therapy tailored to address pelvic floor overactivity, and sexual and relationship difficulties. More recently, the therapeutic use of placebo is gaining traction in chronic pain research and is a very promising adjunctive therapy. The majority of women with PVD are managed outside of tertiary clinic settings, and care depends on availability and affordability of specialized services; however, much can be done by the primary health provider. PVD is common, and highly treatable, especially with early intervention, but unfortunately, many clinicians are unaware of this condition, and the biggest hurdle for women accessing treatment is obtaining a diagnosis. With treatment, most women can expect significant improvement, often with fairly simple interventions, although some women will benefit from referral to specialized centers. The aims of this article are twofold: firstly, to summarize current literature concerning PVD pathophysiology and management; secondly, to provide a framework for clinicians unfamiliar with vulvar medicine to understand and manage PVD.

Keywords: vulvodynia, pathophysiology, comorbidities, clinical subtypes, placebo, physiotherapy
\end{abstract}

\section{Introduction}

The International Society for the Study of Vulvovaginal Disease (ISSVD) proposes two categories of persistent vulvar pain: vulvar pain caused by a specific disorder (such as infection or dermatitis) and vulvodynia. ${ }^{1}$ Vulvodynia is defined as "vulvar pain of at least 3 months duration, without clear identifiable cause, which may have potential associated factors". This definition makes reference to factors potentially involved in pain pathogenesis and will be discussed later.

Vulvodynia is further classified depending on whether pain is localized (to the vestibule or clitoris) or generalized (to the whole vulva), and whether pain is provoked by touch or occurs spontaneously. ${ }^{1}$ Provoked pain localized to the vaginal entrance, ie, provoked vestibulodynia (PVD), is the most prevalent subtype of vulvodynia ${ }^{2}$ and the focus of this article. In contemporary literature, PVD is also referred to as localized provoked vulvodynia or localized provoked vestibulodynia (LPV). Older terms no longer in use are vulvar vestibular syndrome, and vestibulitis or vulvar vestibulitis.

In PVD, pain occurs in the vulvar vestibule, most often triggered by attempted vaginal penetration, be it tampon insertion, sexual activity or speculum examination.
Correspondence: Helen Henzell Melbourne Sexual Health Centre, 580 Swanston Street, Carlton, VIC 3053, Australia

Tel +6I 3 934| 6200

Email hhenzell@mshc.org.au
International Journal of Women's Health 2017:9 63I-642 Dovepress in http://dx.doi.org/|0.2147IJWH.SI13416. (c) (1) (5) 2017 Henzell et al. This work is published and licensed by Dove Medical Press Limited. The full terms of this license are available at https://www.dovepress.com/terms.php cc) ${ }_{\mathrm{BY}} \mathrm{NC}$ and incorporate the Creative Commons Attribution - Non Commercial (unported, v3.0) License (http://creativecommons.org/licenses/by-nc/3.0/). By accessing the work you hereby accept the Terms. Non-commercial uses of the work are permitted without any further permission from Dove Medical Press Limited, provided the work is properly attributed. For permission for commercial use of this work, please see paragraphs 4.2 and 5 of our Terms (https://www.dovepress.com/terms.php). 
The majority of women continue to have sex $;^{2}$ however, in a significant minority, provoked pain is of such severity and is so distressing that they cannot tolerate sexual intercourse. There is often no pain in the absence of touch, although for some women, there can be a background of spontaneous (or unprovoked) discomfort that may be described as an "unpleasant awareness". Pain is often described as burning or raw, also irritating, itchy, a feeling of pressure or sharp or stabbing or tearing pain. ${ }^{3}$ Burning can continue after sexual activity, lasting from minutes to days. Some women experience vulvar dysuria or urethral stinging or urinary frequency immediately after sex. Women may describe a feeling that something is blocking their vagina when they attempt sex. This is usually due to pelvic floor overactivity or spasm, rarely an imperforate hymen.

PVD onset can be primary or secondary depending on whether pain has been present since first sexual activity or tampon use (primary PVD), or after a period of pain-free sex (secondary PVD). ${ }^{1}$ The importance of this distinction is that pathophysiology, severity of symptoms and response to treatment may be different. ${ }^{4}$

A classification for sexual pain is provided in the Diagnostic and Statistical Manual of Mental Disorders, 5th edition (DSM-5), namely “genito-pelvic pain/penetration disorder", listed as a sexual dysfunction. ${ }^{5}$ Vulvodynia is not mentioned as a differential diagnosis despite it being one of the most common causes of sexual pain. ${ }^{6}$ Using the DSM-5 terminology, vulvodynia could be classified as a psychiatric disorder and a sexual dysfunction. This has proved controversial. ${ }^{7} \mathrm{We}$ believe that to classify vulvar pain as a psychiatric disorder is neither helpful nor informative, and does not lead clinicians to adopt a contemporary evidence-based approach to management.

\section{Prevalence}

Vulvodynia is common and affects women of all ages. Population-based surveys suggest vulvodynia affects between 6 and $8 \%$ of women at any one time, and up to $25 \%$ in their lifetime, ${ }^{2,8}$ with most of the pain being provoked. ${ }^{2}$ Annual incidence seems to be in the order of $3 \% .{ }^{9}$ Incidence is higher in young women. ${ }^{10,11}$ There is a second peak of vulvar pain around menopause, in part due to vulvovaginal atrophy but also new-onset or recurrent vulvodynia. ${ }^{12}$ Vulvodynia can occur in childhood, but studies are sparse, and in many cases, persistent pain is found to have an underlying cause. ${ }^{11}$

Vulvodynia often remits spontaneously, but relapse is common. In one prospective study that followed 239 women with vulvodynia every 6 months for 2 years, $10 \%$ had persistent pain (ie, reported pain at every visit), and $90 \%$ experienced remission but about half of these relapsed, often within a short space of time. ${ }^{3}$ These are higher rates of remission than previously reported, much of the discrepancy attributed to inconsistent reporting of prior pain once women are pain-free. Pain of longer duration and greater severity is more likely to persist. ${ }^{3}$

New-onset vulvodynia is noted more commonly in women with preceding intermediate vulvar symptoms suggesting an identifiable prodromal phase for some women (intermediate symptoms defined as recent pain with or after intercourse, or characteristic vulvar pain for less than 3 months). ${ }^{10}$ Pain with first tampon use is also reported more frequently in women who later develop vulvodynia. ${ }^{9}$ Other factors associated with vulvodynia onset include a history of candidiasis, presence of comorbid chronic pain conditions, sleep disturbance and mood disorders. ${ }^{8,10}$

Access to treatment relies on diagnosis, and unfortunately, this is a major problem with vulvodynia. Survey data reveal that about half of women do not seek medical assistance, and of those that do, only a small number are diagnosed. ${ }^{2}$ The low rate of diagnosis is attributed to several factors including practitioner unfamiliarity with this condition, but also because many women do not describe their discomfort as "pain", but in other terms such as "rawness" or "irritation" as previously discussed.

\section{Pain neurobiology}

It is helpful if the clinician understands and is able to explain chronic pain theory to a woman diagnosed with PVD. To give a rational explanation of how pain can persist in the absence of infection or trauma helps de-escalate anxiety, which is known to mediate chronic pain.

Pain can be broadly divided into three categories: nociceptive, inflammatory and pathological. ${ }^{13}$

- Nociceptive (or acute) pain is an early-warning physiological protective response to noxious stimuli.

- Inflammatory pain is an adaptive physiological response to inflammation with heightened sensitivity that discourages movement and physical contact with the injured area until healing has occurred.

- Pathological pain is a maladaptive response of an abnormally functioning nervous system, and is of two types:

- Neuropathic pain that occurs after a lesion or disease of the nervous system.

- Dysfunctional pain that occurs in the absence of a noxious stimulus and no, or minimal, peripheral inflammatory pathology. 
PVD is a dysfunctional pain. In earlier literature, PVD has been described as neuropathic pain, but this description is confusing based on contemporary definitions as it implies a neural lesion.

It is thought that chronic pain starts with acute pain. ${ }^{14}$ The transition from acute to chronic pain is proposed to involve three interlinked processes: peripheral sensitization, central sensitization and altered descending modulation. ${ }^{14}$

Peripheral sensitization refers to hyperexcitability and lowered sensory threshold of sensory neurons in the periphery, and central sensitization refers to hyperexcitability and increased synaptic efficiency in the central nervous system (CNS). ${ }^{15}$ The effects are synergistic and result in lowered sensory thresholds such that non-painful touch becomes painful (allodynia) and painful touch becomes more painful (hyperalgesia). Changes in the dorsal horn lead to wind up (increased perceived pain intensity over time with repeated stimulation), spontaneous pain, afterpain (pain continuing after cessation of stimulus) and expansion of nociceptive fields resulting in secondary hyperalgesia and convergence (spread of pain to adjacent structures). These changes reflect neuroplasticity, a feature of the nervous system whereby neurons can change in structure and function. ${ }^{14}$ The result is that the sensation of pain is uncoupled from noxious stimuli and arises instead from innocuous peripheral input, or spontaneously.

Descending modulation (ie, "top-down" facilitation or inhibition of nociception in the spinal cord) can alter the sensory experience. Pain perception can be enhanced or diminished depending on anticipation, attention (and distraction), emotional state, mood, anxiety, coping style, outlook, tendency to catastrophize, learning and memory. ${ }^{16}$ This has proved a fruitful area for psychological intervention and underpins placebo effect (which is possibly better described as anticipation of benefit).

Brain imaging has become increasingly important in the study of chronic pain. Few studies have been undertaken in women with PVD, and are summarized by Walitt et al. ${ }^{17} \mathrm{Cen}-$ tral processing of acute pain and chronic pain has been shown to occur in different areas of the brain, despite the pain feeling the same. ${ }^{18}$ With the transition of acute to chronic pain, brain activity shifts from the sensory representation areas of the brain to areas more associated with emotion and evaluation. ${ }^{19}$ This may in part explain why treatments that work for acute pain do not work well for chronic pain. ${ }^{18}$ Central imaging has shown subtle changes in white and gray matter volumes associated with chronic pain, but these changes appear to be reversible with pain reduction. ${ }^{20}$
Neurons do not act in isolation, and accumulating evidence points to involvement of non-neuronal cells in initiation and maintenance of chronic pain. In the skin, a complex interplay between nociceptors, epithelial cells and immune cells is thought to be involved in peripheral sensitization. ${ }^{21}$ In the CNS, neurons are closely associated with glial cells, and there is increasing evidence that activation of spinal glia increases synaptic efficiency and pain transmission. ${ }^{22}$ Mast cells are also implicated in pain sensitization, both in the peripheral nervous system and the CNS. ${ }^{23}$ With better understanding of these complex interactions involved in pain pathogenesis, new therapeutic targets are emerging that hold promise for pain management.

\section{Potential associated factors and pathophysiology}

In the last few years, several excellent summaries of pathophysiological factors associated with PVD have been published. ${ }^{24-26}$ Much of the literature regarding pathophysiology relates to chronic pain in general, or other chronic pain conditions, and not PVD specifically. We indicate where PVD is discussed.

Chronic pain affects $\sim 20 \%$ of the adult population. ${ }^{27}$ Central mechanisms appear similar, but site of the pain (the phenotype) varies. ${ }^{28}$ While our understanding of chronic pain pathophysiology has advanced, much remains to be understood. No single causative factor for PVD, or chronic pain in general, has been identified, and pathophysiology is likely multifactorial and complex, and differs from person to person. It has been proposed that multiple genetic factors in concert with environmental exposures (such as infection, trauma and psychological stress) enhance pain sensitization and/or psychological distress to increase susceptibility to chronic pain. ${ }^{29}$ With greater understanding of the pathophysiology, it may become possible to individualize treatments. Accordingly, we will discuss PVD subtypes in management.

\section{Genetic factors}

There is mounting evidence of genetic vulnerability in chronic pain, and multiple genetic polymorphisms have been associated with pain sensitivity. ${ }^{30}$ The risk for developing chronic pain appears to be moderately heritable. ${ }^{31}$ Certain polymorphisms in genes that code for neurotransmitters and their receptors, as well as those coding for inflammatory cytokines and nerve growth factors, have been detected more frequently in people with chronic pain. ${ }^{30}$ Most of this work has been conducted in people with migraine, fibromyalgia, 
temporomandibular disorders and chronic low back pain. There is little information on genetic polymorphisms in PVD. A search of the Human Pain Genetics Database ${ }^{32}$ gives five results for genetic polymorphisms in serotonin and $\mu$-opioid receptor genes that are associated with PVD.

\section{Psychosocial factors}

Psychological states influence pain sensitivity, and psychological distress increases the risk for transition of acute to chronic pain. ${ }^{33}$ Chronic pain is highly comorbid with anxiety and depression, and visa versa. ${ }^{34}$ Premorbid anxiety disorder is 10 times more common and depression three times more common in women with PVD compared with controls. ${ }^{35}$ Adverse childhood experiences including abuse, living in fear of abuse and social trauma (bullying, exclusion or lack of support) are also risk factors for chronic pain and PVD. ${ }^{36}$

Posttraumatic stress disorder (PTSD) is a form of severe anxiety, leading to fear-avoidance behaviors. ${ }^{34}$ Although best known as affecting combat veterans, the rates of PTSD affecting nonveteran women may be higher, particularly after sexual assault where PTSD has been estimated to affect between 30 and 44\% of women. ${ }^{37}$ Premorbid PTSD has two to three times higher risk for PVD development. ${ }^{35}$ Co-occurrence of PTSD and chronic pain is associated with increased pain levels and pain disability. ${ }^{38}$

Pain catastrophizing deserves a special mention, as it is a well-established risk factor for increased pain perception. ${ }^{39}$ Pain catastrophizing is characterized by a sense of helplessness when in pain, anxious preoccupation with pain, magnification of the negative effects of pain, and an inability to inhibit pain-related fears. ${ }^{39}$ It is a strong predictor of poor response to treatment. ${ }^{40}$ Catastrophizing is an accepted and standard term, but we feel this word carries a potential for derogatory and non-compassionate judgment of the patient.

\section{Sleep}

Sleep quality influences pain and central sensitization, and poor sleep adversely affects both domains. ${ }^{41}$ Sleep deprivation promotes hyperalgesia and anxiety. ${ }^{42}$

\section{Comorbid chronic pain}

Almost half of women with vulvodynia report one or more other chronic pain conditions. ${ }^{43}$ Pain begets pain, and the presence of one chronic pain condition is a well-established predictor for onset of a new pain condition. ${ }^{9,29}$ Mounting evidence demonstrates genetic vulnerability, with significant rates of overlap among a cluster of prevalent pain conditions that predominantly affect women. These have been termed chronic overlapping pain conditions (COPCs). ${ }^{44}$ These conditions include vulvodynia, temporomandibular disorders, myalgic encephalomyelitis/chronic fatigue syndrome, irritable bowel syndrome, interstitial cystitis/painful bladder syndrome, fibromyalgia, endometriosis, chronic tension-type and migraine headache and chronic low back pain. It is proposed that these conditions share altered neural, immune and endocrine mechanisms that result in sensory processing dysfunction and pain. ${ }^{44} \mathrm{~A}$ common feature in patients with chronic pain is enhanced pain sensitivity distant to the primary pain site, ${ }^{15}$ and this has been demonstrated in PVD. ${ }^{45}$ Another shared feature is that pain is exacerbated by stress. ${ }^{29}$ In addition to the symptom of pain, many people experience fatigue, sleep impairment, problems with cognition, physical dysfunction and disturbance in affect. ${ }^{29}$ These associated symptoms, attributed to central sensitization, ${ }^{28}$ are present to a greater or lesser extent depending on severity and number of chronic pain conditions. ${ }^{44}$

\section{Peripheral factors}

\section{Vulvar vestibule}

The vulvar vestibule is immunologically unique and exhibits an enhanced immune-inflammatory responsiveness that may predispose to PVD. ${ }^{46}$ The role of vulvovaginal candidiasis in PVD pathogenesis has long been suspected. Increased prevalence is observed in women with PVD. ${ }^{8,9}$ There is mounting evidence of an exaggerated local immune response to candida in women with PVD, and it has been proposed that this heightened immuno-inflammatory response may trigger peripheral sensitization. ${ }^{46,47}$

\section{Pelvic floor (PF) muscle overactivity}

PF muscle overactivity may play a role in initiating or perpetuating, or be a consequence of vulvar pain. An overactive $\mathrm{PF}$ is a hallmark sign of vulvodynia. ${ }^{48}$ The pathophysiology is not confirmed and is likely multifactorial. Several mechanisms have been suggested. Psycho-emotional distress alone can induce increased muscle activity, and the PF has been shown to be highly sensitive to emotional distress. ${ }^{49} \mathrm{PF}$ guarding can occur in response to actual (eg, candidiasis) or perceived vulvar tissue damage. At first this response can be regarded as adaptive but over time it becomes maladaptive. It is suggested that sustained muscle contraction triggers an inflammatory response due to motor end plate damage leading to dorsal horn sensitization. ${ }^{50}$

Inflammation of local vulvar mucosa may sensitize nearby muscle nociceptors causing PF contraction; conversely, 
an overactive PF may lead to mucosal sensitization via convergence at the dorsal horn, and a vicious cycle can ensue. ${ }^{51}$ Convergence is variably implicated in the complex relationship between vulvar pain, the CNS, the pelvic viscera and internal and external muscles of the pelvis. ${ }^{50}$ This convergence, ordinarily a useful cross talk between organs, can lead to pain being referred to muscles from painful visceral conditions or deep somatic structures. ${ }^{52}$

\section{Hormonal factors}

Hormonal factors may be implicated in pain initiation, but this relationship is not clear. Estrogen reduces activation of $\mu$-opioid receptors in response to pain and has an anti-dopamine effect, and this may play a role. ${ }^{33}$ There is conflicting evidence about the role of combined hormonal contraception (the pill) in vulvodynia, with some research showing increased vulvodynia in pill users, ${ }^{8,53}$ and other research showing no increase. ${ }^{54}$ The pill is often prescribed for dysmenorrhea, and this may act as a confounder as dysmenorrhea (specifically endometriosis) is associated with vulvodynia. ${ }^{44}$ The literature pertaining to putative explanations for increased pain with pill use are summarized by Lev-Sagie and Witkin. ${ }^{24}$

\section{Diagnosis and assessment}

PVD is a clinical diagnosis based on a history of pain localized to the vaginal entrance, provoked by touch or sexual activity. Examination typically shows a normal-looking vulva that is tender with gentle Q-Tip pressure over the inner vestibule adjacent to the hymenal ring (Figure 1). Pain mapping is best started at a non-tender site away from the introitus (eg the outer vulva) working towards the painful area. In PVD tenderness may extend around the introitus or

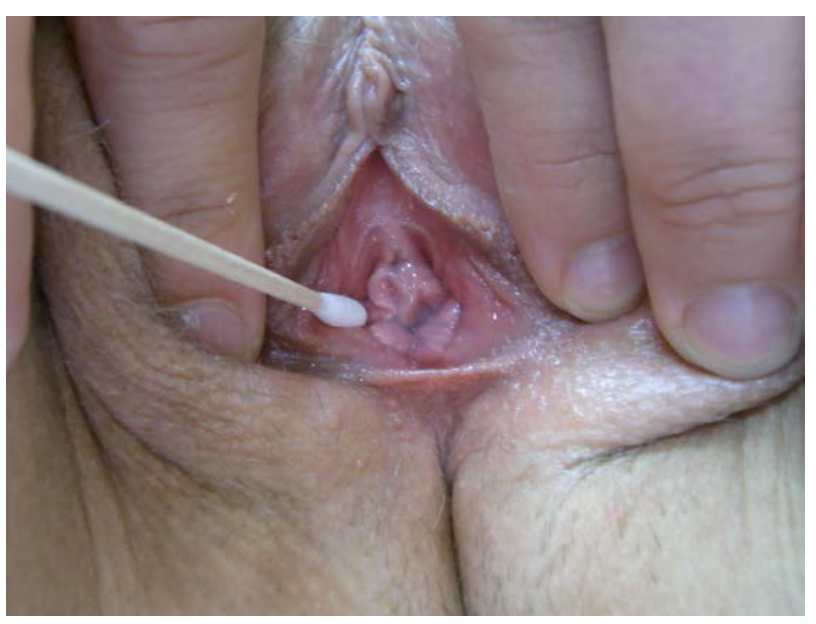

Figure I Mapping of vulvar pain with a Q-Tip, with maximal tenderness at the introitus. be localized to the posterior edge between 5 and 7 o'clock. While important in assessment, the authors caution against unnecessary repeat Q-Tip testing as this can result in an unhelpful hypervigilance to vestibular sensitization.

There can be localized erythema at the maximal points of introital sensitivity which is a nonspecific finding related to pain. The PF muscles are typically tense and tender with gentle palpation. Speculum examination can cause significant pain and should be avoided if possible. There are no specific diagnostic tests. Any investigation should be directed at confirming or excluding other pathologies, such as candidiasis, painful dermatoses or rarely pudendal neuralgia. PVD can be concurrent with these vulvar disorders, which will need cotreatment. Any local inflammatory skin condition can cause inflammatory pain. Of specific importance is the diagnosis of recurrent/chronic vulvovaginal candidiasis (RVVC) as this is implicated in peripheral sensitization and PVD. ${ }^{47}$ Diagnosis can be tricky as there are often few signs, and cultures can be negative with recent antifungal use. ${ }^{55}$

Clinical history should search for any contributing factors and vulnerabilities such as comorbid chronic pain, chronic stressors (anxiety, depression, past trauma and PTSD) and sleep impairment. Detailed trauma history is beyond the scope of this article, and we recommend referral if significant trauma is suspected. Many people who have experienced trauma, especially recurrently in childhood, may unconsciously downplay their experience, or find it difficult to discuss past experiences without being re-traumatized. ${ }^{56}$

With examination, we recommend using a mirror, and this has several therapeutic purposes. Firstly, many women are unaware of their vulvar anatomy and have not looked at their vulva closely, if at all. Secondly, chronic pain can be difficult to localize, and it is often informative for a woman to see where her pain is. Thirdly, demonstrating that pain is elicited with light touch, and that the painful skin looks normal, illustrates that pain is due to neural sensitization and not damage. Finally, she can be shown where to apply topical treatments for maximal effect, for example, local anesthetic applied deep into the introital sulcus between the hymenal ring and inner vestibule. This can be demonstrated during examination. The clinician can teach women techniques using their own finger to learn PF relaxation (down training) and to begin desensitization as a prelude to physiotherapy.

It should be noted that sometimes vulvar pain is of such severity, or fear of examination so overwhelming, that examination is not possible on a first visit. It is important that women give genuine informed consent to examination and feel empowered to stop the examination at any point. 
Table I PVD clinical subtypes

\begin{tabular}{ll}
\hline Uncomplicated PVD & Complicated PVD \\
\hline Short-duration PVD & Longer-duration PVD \\
Milder pain severity & Greater pain severity ${ }^{57}$ \\
0-I comorbid pain condition & Two or more comorbid pain \\
& conditions \\
None or mild current & Significant comorbid psychological \\
depression and/or anxiety, & or emotional factors - anxiety, \\
good social supports & depression, PTSD, fear-avoidance, \\
& catastrophizing, poor social supports \\
No trauma history & Past or present trauma \\
Well-controlled candidiasis & Painful dermatoses (eg, lichen planus \\
& or plasma cell vulvitis) or refractory \\
& candidiasis not responding to \\
treatment
\end{tabular}

Abbreviations: PVD, provoked vestibulodynia; PTSD, posttraumatic stress disorder; $\mathrm{PF}$, pelvic floor.

\section{PVD clinical subtypes}

History and examination can reveal patterns or broad subtypes of PVD that can help inform management. We propose a clinical triage tool (Table 1) that categorizes PVD into uncomplicated or complicated subtypes.

A simpler algorithm we suggest for grouping PVD into broad subtypes is:

1. predominantly overactive $\mathrm{PF}$;

2. predominantly peripheral inflammatory mechanisms (eg, chronic candidiasis);

3. significant psychosocial and emotional factors ( see Table 1);

4. painful comorbidities (COPCs) suggestive of genetic vulnerability.

Subtypes 1 and 2 are often uncomplicated forms of PVD where peripheral sensitization is predominant and can usually be managed in primary care, including physiotherapy. Subtypes 3 and 4 suggest complicated PVD and often require specialist assessment; however, tertiary referral may not be required if there is a multidisciplinary network of clinicians in the community who are experienced in managing PVD (such as psychologists, physiotherapists and pain physicians).

\section{Management}

The aim of treatment is to reduce pain, and improve quality of life and sexual function. No single treatment is effective for all women. ${ }^{58}$ There is good evidence that multidisciplinary management is effective. ${ }^{59}$ Current treatment guidelines for PVD recommend individualized and multidisciplinary care that includes physical, psychological and pharmacological therapies. ${ }^{60-62}$ Studies that inform PVD treatment guidelines are often small with limited statistical power, and have different methodologies that include heterogeneous groups, making generalizability difficult. PVD subtypes are rarely considered. Despite these limitations, most women do improve with treatment, and many become pain-free. ${ }^{63}$ However, treatment goals need to be realistic from the outset as response to treatment can be slow, particularly for women with complicated PVD.

\section{General measures}

Good genital skin care should be recommended for all women (some websites for information are given in the "Resources" section). The basic advice is to avoid irritants and improve moisture. We recommend women to temporarily stop sexual activity if it is causing distressing pain and look at non-painful intimacy. Good lubrication with sexual activity is important as friction can increase discomfort, but one should be mindful that some lubricants can irritate. Concurrent inflammatory skin conditions, particularly vulvovaginal candidiasis, need to be managed as this may result in substantial, if not complete, reversal of pain. A trial of suppressive antifungal therapy is worthwhile if there is any suggestion of RVVC on history. ${ }^{64}$ Oral treatment is preferable as prolonged topical antifungal therapy may irritate.

It is important to counsel women that pain can flare with stress, but to also consider recurrent or new peripheral nociceptive contributors to pain. These include dermatitis, candidiasis, sexually transmitted infections and urinary tract infections. It is important to review women when they have a flare of pain that does not settle.

\section{Education}

Increasing a woman's belief that she can influence her pain is a key to successful management, and has been shown to reduce pain intensity. ${ }^{63}$ There is compelling evidence for neuroscience education in reducing pain, disability, anxiety and stress. ${ }^{65}$ Education reduces sexual and psychological distress. ${ }^{66}$ Consistent empathic interaction and continuing tailored education about pain neurobiology promote lasting self-efficacy as well as maximal placebo response. Education needs to be tailored and at a level the woman can comprehend, as it is often an extreme paradigm shift that can be rejected. To have a name for the pain, to know that PVD is common and that with treatment most women can expect significant improvement may provide enormous relief and reduce pain-related anxiety, and pain itself. Explaining how pain can occur in the absence of peripheral pathology (such as cancer, infection or trauma) and why certain treatments might work sets the stage for improved therapeutic response. 
The aim is for the woman to understand, rather than just cope, so she can transition to being a less fearful, more informed self-manager of her pain.

\section{Placebo effect}

It is appropriate to discuss placebo effects in any management plan for chronic pain. ${ }^{67} \mathrm{With}$ all treatment interventions, there is an element of placebo, particularly with pain and mood disorders, and this should be viewed positively. There is good evidence for why placebo works, especially in pain and behavioral studies. Placebo effects rely on complex neurobiological mechanisms involving neurotransmitters (eg, endorphins and dopamine) and activation of specific areas of the brain involved in emotion and evaluation (ie, the same areas activated in chronic pain) ${ }^{68}$ Placebo has been shown to work when trial participants are fully informed on the nature of placebo. ${ }^{69}$ Importantly, placebo effect is enhanced when the clinician adopts an emotionally warm and empathic style. . $^{6,69}$

Placebo can be viewed as an adjunctive intervention in the treatment of PVD. Explaining the rationale of why a treatment might work introduces positive expectation (ie, placebo), and this expectation can be enhanced by the communication style of the clinician. ${ }^{68}$ In effect, the clinician becomes a therapeutic agent in the way they relate to patients in connection with providing effective treatment interventions. ${ }^{68}$ Empathy has been shown to activate the same brain regions as activated in chronic pain and placebo. ${ }^{70}$ Nocebo (the opposite of placebo) is of concern in the management of PVD where there is clinician uncertainty regarding diagnosis and management. Messages of uncertainty can potentially induce nocebo hyperalgesia. ${ }^{71}$

\section{Topical treatments}

The simplest intervention is topical therapy. Lidocaine is the most commonly used. Some authors do not recommend continued use due to lack of evidence, ${ }^{60}$ but when used on an as-needs basis (ie, before sex), some women experience significant improvement. ${ }^{72}$ In our clinical experience, many women who use topical lidocaine prior to sexual activity have less provoked pain, and sometimes, sex is pain-free. It can also assist with physiotherapy in very sensitized women. Lidocaine $2 \%-5 \%$ gel or ointment can be applied 10-20 minutes before sex or physiotherapy. Women should be warned that it may sting briefly and treatment should be stopped if irritating. We advise women to wipe off any excess before sexual activity as it may numb the partner.

Various neuromodulating medications, such as amitriptyline, gabapentin or baclofen, can be used topically, but evidence of benefit is limited and this approach is not recommended as first-line therapy. ${ }^{58,60,61}$ They are compounded in a neutral base in various strengths (usually $2 \%-5 \%$ ) and applied in various regimens (usually at night or twice daily) to the vestibule. ${ }^{58}$ Topical application has the added benefit of promoting self-touch, massage and desensitization. It may act as the therapeutic ritual to promote placebo effect. Again, treatment should be stopped if irritating.

Topical capsaicin is under investigation but not yet recommended for treatment of PVD as evidence is limited and side effects are significant. ${ }^{58}$ Topical cromolyn cream (a mast cell stabilizer) is also being investigated, but again, evidence of benefit is limited. ${ }^{60}$ Palmitoylethanolamide, an endogenous anti-inflammatory compound, is showing some promise as a topical and systemic agent, but larger trials are needed. ${ }^{21}$

\section{Physiotherapy}

PF physiotherapy has Grade B recommendation ${ }^{1}$ in managing vulvodynia and is effective and recommended as part of a multidisciplinary approach. ${ }^{60}$ The physiotherapist makes treatment decisions considering the complexity of PVD and comorbid pain conditions. Treatment is multimodal depending on perpetuating factors that may upregulate pain, including factors beyond PF muscle overactivity (Table 2).

The PF forms part of an integrated neuromuscular system with functions including mechanical support, mobility, reproduction, respiration, evacuation as well as sexual function. Specialist skills are required in pelvic and general physiotherapy as well as chronic pain management. Treatment considers related systems and central pain mechanisms. A biopsychosocial and contextual physiotherapy approach includes education, pain management and safe and graded functional rehabilitation for women (Table 3).

With regular contact, the physiotherapist is in a privileged and valuable position to develop trust and rapport.

Table 2 Potential contributing factors

Altered biomechanics (gait, posture, core, respiration, prolapse)
Muscular response to stress
Maladaptive guarding to pain (especially abdominals and intra-/extra-
pelvic muscles)
Poor sports training techniques/overtraining
History of overactivation (eg, elite sports, intense childhood regimes
such as ballet/gym)
Constant abdominal activation to appear slimmer
Injury or dysfunction (current or previous): spinal, hip, pelvic, lower
limbs, obstetric
Surgical: repeated sensitizing events, persistent postoperation muscle
guarding
Attempting core exercises when overactivity is already present


Table 3 Physiotherapy treatments

Education

Pelvic floor rehabilitation

Posture and breathing techniques

Bladder and bowel training

Voiding and defecation dynamics

Good bladder and bowel habits

Lifestyle/behavior modifications

Treatment of musculoskeletal dysfunction

Stress reduction strategies

Vulvar skin care

Adjunctive therapies

Self-management of pain flares

Guided exercise and reconditioning

The physiotherapist may be the first person to whom fear and abuse are revealed, equally, the work associated with physiotherapy may trigger memories of trauma. The physiotherapist needs to have strategies to manage these events should they occur, and referral networks for counseling.

PF overactivity contributes to PVD. Physiotherapy, whilst widely accepted as an effective treatment intervention for PVD, requires larger randomized trials to determine efficacy of specific modalities. ${ }^{73}$ There is evidence of improved sexual function and reduced pain with intercourse with PF therapy. ${ }^{74}$ PF therapy aims to increase awareness and proprioception, normalize tone, improve muscle discrimination and reduce fear of penetration. Combinations of manual therapy techniques for the PF may be used including awareness training, down training, stretching and myofascial release. Down training involves teaching reduced maladaptive resting and dynamic overactivity to learn a new optimal resting state. Strategies should include retraining in functional tasks. Debate remains over the physiological effect of myofascial techniques, but trigger-point therapies and Thiele massage for PF overactivity are described in the literature. ${ }^{75}$ It should be noted that vulvar pain can be very distressing, and myofascial techniques should be applied in a manner that is well tolerated. The aim is to reduce overactivity and desensitize the CNS. ${ }^{76}$ Adjunctive therapies may be employed including transcutaneous electrical nerve stimulation (TENS), electromyographic (EMG) biofeedback and dilators. Topical lidocaine may be a valuable adjunct to help override a vaginismus response.

If suitable to the couple, the partner can be involved in the treatment at home, but one should be mindful that this can medicalize their intimacy. Also, some women may fear that involving partners in physical treatment may lead toward unintentional sexual arousal of the partner. Safe boundaries need to be agreed upon beforehand.

\section{Psychological therapies}

We encourage all women to look at self-management strategies to reduce anxiety and stress. This includes relaxation, mindfulness and meditation. Good refreshing sleep is important in addressing chronic pain. Identification of significant mood disorders, chronic stress, unhelpful pain cognitions and catastrophizing are a priority in management and require intervention, and referral if necessary.

Psychological interventions for vulvodynia are effective and recommended as a treatment modality. ${ }^{60,77}$ Many psychological approaches are available. ${ }^{60}$ Both cognitive behavioral and supportive therapies result in improvements in depression, anxiety, sexual function and pain. ${ }^{77}$ Women who experience fear and pain avoidance can dissociate from their body sensations with sexual arousal, especially in the presence of PTSD,${ }^{78}$ and may respond to mindfulness-based therapy. ${ }^{79}$ Psychotherapy that promotes acceptance of the pain and a reduced sense of injustice "why me" has been shown to improve sexual function. ${ }^{80,81}$

\section{Sexual and relationship counseling}

Encouraging the partner to attend one or more sessions, and educating the partner about pain neurobiology, is often helpful for both the woman and the partner. A combined consultation can provide a safe place for them to discuss the effect of pain on their sexual intimacy and relationship. If penetrative sex is too painful, an exploration of intimacy that is not painful can be discussed with the couple. ${ }^{82}$ As discussed above, the partner can be involved in hands on PF work and desensitization. If there are significant relationship difficulties, or sexual problems that seem beyond the effect of pain, one should consider referral for more in-depth counseling.

PVD is not necessarily associated with general relationship difficulties, ${ }^{83}$ and pain intensity does not always predict sexual satisfaction or dissatisfaction. ${ }^{80}$ Improving pain does not always improve sexual function. ${ }^{84}$ Good intimacy predicts continuing sexual activity despite pain and poor sexual satisfaction. ${ }^{85}$

\section{Oral treatments}

Recent comprehensive vulvodynia management guidelines comment on the paucity of controlled trials in vulvodynia that limit conclusions about the effectiveness of oral neuromodulating agents. ${ }^{60,86}$ International reviews of neuropathic pain pharmacotherapy indicate there are problems interpreting trial results; however, they conclude there is modest efficacy and large placebo responses. ${ }^{87,88}$ Anticonvulsant therapies (including gabapentinoids), tricyclic antidepressants (TCAs) 
and selective norepinephrine reuptake inhibitors (including duloxetine and venlafaxine) are considered first line in the treatment of chronic pain, ${ }^{87}$ but not in vulvodynia as evidence of benefit is lacking. ${ }^{60}$ If used, it is important to discuss that in the setting of chronic pain, these medications are used as pain neuromodulators and not as anticonvulsants or antidepressants. They are usually prescribed in lower dose than would be used for epilepsy or mood disorders. In general, TCAs cannot be combined with selective serotonin uptake inhibitors owing to the risk of serotonin syndrome, but can be combined with gabapentinoids.

\section{Surgery}

There is fair evidence for vestibulectomy in improving pain and sexual function in women with PVD. ${ }^{60}$ It is usually considered after other treatments have failed. The evidence is limited due to methodological factors including lack of controls, varying surgical procedures and lack of data on longer-term outcome. One study that did look at longer-term outcomes concluded that women with severe vestibulitis who have not responded to conservative management may benefit from vestibulectomy, but noted no difference in sexual outcomes with surgery. ${ }^{89}$ Further robust studies using controls are required.

\section{EMG biofeedback}

EMG surface or internal biofeedback is widely used for managing PVD to provide feedback and facilitate PF relaxation. Several studies report decreased pain with intercourse. ${ }^{84,90}$ There is mixed evidence for its value in PVD, but care in its utilization is recommended as tolerability of an insertable probe must be considered in the patient with a sensitized vulva. The evidence shows poor compliance with home use. ${ }^{91}$

\section{Dilators (trainers)}

Dilators (trainers) are widely used in managing PVD, although evidence is limited. A small study used a prescriptive program using trainers in vestibulodynia and found improved scores on the Marinoff Dyspareunia Scale and Female Sexual Function Index. ${ }^{92}$ The authors agree with Rosenbaum $^{93}$ that their application should be clinically supported and contextual. Trainers are rarely used in PVD to gain capacity through stretch. Rather, drawing on broader graded exposure principles, ${ }^{94}$ we propose they can be used in a functional sense to:

- provide a stimulus that does not elicit pain, providing an opportunity to learn a new way to respond (without fear or guarding);
- provide proprioceptive feedback to learn to override protective muscle guarding;

- achieve improved sensory tolerance (with graded exposure) to the temporal and/or mechanical contributions to penetration pain;

- uncouple a conditioned response (pain and penetration) with painless graded exposure. We find topical lidocaine is a helpful adjunct in this process.

Women can use their own fingers if preferred to dilators for home therapy.

\section{Transcutaneous electrical nerve stimulation}

There are small studies showing improvement in pain and sexual function in women with vulvodynia using TENS, ${ }^{95,96}$ but the literature regarding TENS as a treatment modality in vulvodynia is limited and further studies are needed.

\section{Emerging modalities}

There are treatment modalities with growing interest but limited evidence, including hypnotherapy and acupuncture. Small studies show positive but limited outcome improvements with acupuncture for PVD. ${ }^{97,98}$ There is early work looking at deep brain stimulation, spinal cord stimulators, transcranial magnetic stimulation, somatosensory psychotherapy, ${ }^{99}$ mindbody therapies (including yoga and tai chi) and Botulinum Toxin A, but with no long-term trials in PVD. The last has emerging evidence in recalcitrant pelvic pain. ${ }^{100}$

\section{Summary}

- PVD is a common but underdiagnosed chronic pain condition that affects women of all ages.

- Pathophysiology is complex and likely multifactorial.

- An individualized and multidisciplinary approach to management is recommended.

- The patient-clinician relationship is an important aspect of care, and clinician empathy promotes improved outcomes.

- There is good evidence that pain education is an effective intervention.

- Various treatment options are available for PVD, the main ones being physiotherapy, psychological interventions, topical and/or oral pain-modulating medication and surgery.

- Physical and psychological therapies have the best evidence for improved outcome and are recommended as first-line treatment options.

- Surgery is also recommended but is usually reserved for women who have not responded to other treatments. 
- All interventions include elements of placebo, and this can be used to advantage.

- The outlook is generally positive whatever treatment is used.

\section{Resources Useful websites}

- National Vulvodynia Association: https://www.nva.org/ (comprehensive information, learning tools, resources, research updates on vulvodynia).

- Vulvovaginal disorders: http://vulvovaginaldisorders. com/ (comprehensive resources, patient handouts).

- Headspace: https://www.headspace.com/ (mindful awareness).

- Smiling Minds: https://smilingmind.com.au//mindful awareness for younger people).

- Labia Library: http://www.labialibrary.org.au// (images showing healthy variations of normal vulvae).

- Pelvic Pain Foundation: http://www.pelvicpain.org.au/.

\section{Pain education resources}

- 10 things you (and your health care provider) should know about vulvodynia, vestibulodynia, pain and your brain (http://pelvichealthsolutions.ca/wp-content/ uploads/2015/03/Mind-Body-Fact-Sheet-APascale-Jan2014.pdf).

- Understanding pain in 5 minutes or less (https://www. youtube. $\mathrm{com} /$ watch? $\mathrm{v}=5 \mathrm{KrUL} 8 \mathrm{tOaQs})$.

- Explain Pain, by D Butler and L Moseley 2nd ed, 2013; (http://www.noigroup.com/en/Category/EP).

- Why things hurt (https://www.youtube.com/ watch? $\mathrm{v}=1$ ylbrkstYtU).

- Explain pain supercharged (2017; http://www.noigroup. com/explain-pain-supercharged/).

\section{Disclosure}

The authors report no conflicts of interest in this work.

\section{References}

1. Bornstein J, Goldstein AT, Stockdale CK, et al; consensus vulvar pain terminology committee of the International Society for the Study of Vulvovaginal Disease (ISSVD), the International Society for the Study of Women's Sexual Health (ISSWSH), and the International Pelvic Pain Society (IPPS). 2015 ISSVD, ISSWSH and IPPS consensus terminology and classification of persistent vulvar pain and vulvodynia. Obstet Gynecol. 2016;127(4):745-751.

2. Reed BD, Harlow SD, Sen A, et al. Prevalence and demographic characteristics of vulvodynia in a population-based sample. Am J Obstet Gynecol. 2012;206(2):170.e1-e9.

3. Reed BD, Harlow SD, Plegue MA, Sen A. Remission, relapse and persistence of vulvodynia: a longitudinal population-based study. J Womens Health (Larchmt). 2016;25(3):276-283.
4. Pukall CF. Primary and secondary provoked vestibulodynia: a review of overlapping and distinct factors. Sex Med Rev. 2016;4(1): 36- 44.

5. The American Psychiatric Association. Diagnostic and Statistical Manual of Mental Disorders. 5th ed. Arlington, VA: American Psychiatric Association Publishing; 2013.

6. Basson R, Driscoll M, Correia S. When sex is always painful: provoked vestibulodynia. BCMJ. 2016;58(2):77-81.

7. Vieira-Baptista P, Lima-Silva J. Is the DSM-V leading to the nondiagnosis of vulvodynia? J Low Genit Tract Dis. 2016;20(4):354-355.

8. Vieira-Baptista P, Lima-Silva J, Cavaco-Gomes J, Beires J. Prevalence of vulvodynia and risk factors for the condition in Portugal. Int $J$ Gynaecol Obstet. 2014;127(3):283-287.

9. Reed BD, Payne CM, Harlow SD, Legocki LJ, Haefner HK, Sen A. Urogenital symptoms and pain history as precursors of vulvodynia: a longitudinal study. J Womens Health (Larchmt). 2012;21(11): 1139-1143.

10. Reed BD, Legocki LJ, Plegue MA, Sen A, Haefner HK, Harlow SD. Factors associated with vulvodynia incidence. Obstet Gynecol. 2014; 123(2 Pt 1):225-231.

11. Clare CA, Yeh J. Vulvodynia in adolescence: childhood vulvar pain syndromes. J Pediatr Adolesc Gynecol. 2011;24(3):110-115.

12. Mitro SD, Harlow SD, Randolph JF, Reed BD. Chronic vulvar pain in a cohort of post-menopausal women: atrophy or vulvodynia? Womens Midlife Health. 2016;2.

13. Woolf CJ. What is this thing called pain? J Clin Invest. 2010;120(11): 3742-3744.

14. Voscopoulos C, Lema M. When does acute pain become chronic? Br J Anaesth. 2010;105 (Suppl 1):i69-i85.

15. Latremoliere A, Woolf CJ. Central sensitization: a generator of pain hypersensitivity by central neural plasticity. J Pain. 2009;10(9): 895-926.

16. Ossipov MH, Dussor GO, Porreca F. Central modulation of pain. J Clin Invest. 2010;120(11):3779-3787.

17. Walitt B, Ceko M, Gracely JL, Gracely RH. Neuroimaging of central sensitivity syndromes: key insights from the scientific literature. Curr Rheumatol Rev. 2016;12(1):55-87.

18. Hashmi JA, Baliki MN, Huang L, et al. Shape shifting pain: chronification of back pain shifts brain representation from nociceptive to emotional circuits. Brain. 2013;136(Pt 9):2751-2768.

19. Apkarian AV. The brain in chronic pain: clinical implications. Pain Manag. 2011;1(6):577-586.

20. Gwilym SE, Filippini N, Douaud G, Carr AJ, Tracey I. Thalamic atrophy associated with painful osteoarthritis of the hip is reversible after arthroplasty: a longitudinal voxel-based morphometric study. Arthritis Rheum. 2010;62(10):2930-2940.

21. Keppel Hesselink JM, Kopsky DJ, Sajben N. New topical treatment of vulvodynia based on the pathogenetic role of cross talk between nociceptors, immunocompetent cells, and epithelial cells. J Pain Res. 2016;9:757-762.

22. Ji RR, Berta T, Nedergaard M. Glia and pain: is chronic pain a gliopathy? Pain. 2013;154 (Suppl 1):S10-S28.

23. Skaper SD, Facci L, Giusti P. Mast cells, glia and neuroinflammation: partners in crime? Immunology. 2014;141(3):314-327.

24. Lev-Sagie A, Witkin SS. Recent advances in understanding provoked vestibulodynia. F1000Res. 2016;5:2581.

25. Wesselmann U, Bonham A, Foster D. Vulvodynia: current state of the biological science. Pain. 2014;155(9):1696-1701.

26. Pukall CF, Goldstein AT, Bergeron S, et al. Vulvodynia: definition, prevalence, impact, and pathophysiological factors. J Sex Med. 2016;13(3): 291-304.

27. Breivik H, Bond MJ. Why pain control matters in a world full of killer diseases. Pain Clin Updates. 2004;12(4):1-4.

28. Woolf CJ. Central sensitization: implications for the diagnosis and treatment of pain. Pain. 2011;152(3 Suppl):S2-S15.

29. Maixner W, Fillingim RB, Williams DA, Smith SB, Slade GD. Overlapping chronic pain conditions: implications for diagnosis and classification. J Pain. 2016;17(9 Suppl):T93-T107. 
30. Zorina-Lichtenwalter K, Meloto CB, Khoury S, Diatchenko L. Genetic predictors of human chronic pain conditions. Neuroscience. 2016;338:36-62.

31. McIntosh AM, Hall LS, Zeng Y, et al. Genetic and environmental risk for chronic pain and the contribution of risk variants for major depressive disorder: a family-based mixed-model analysis. PLoS Med. 2016;13(8):e1002090.

32. Human Pain Genetics Database. Available from: http://diatchenko.lab. mcgill.ca/hpgdb. Accessed April 8, 2017.

33. Simons LE, Elman I, Borsook D. Psychological processing in chronic pain a neural systems approach. Neurosci Biobehav Rev. 2014;39:61-78.

34. Asmundson GJ, Katz J. Understanding the co-occurrence of anxiety disorders and chronic pain: state-of-the-art. Depress Anxiety. 2009;26(10):888-901.

35. Khandker M, Brady SS, Vitonis AF, Maclehose RF, Stewart EG, Harlow BL. The influence of depression and anxiety on risk of adult onset vulvodynia. J Womens Health (Larchmt). 2011;20(10):1445-1451.

36. Khandker M, Brady SS, Stewart EG, Harlow BL. Is chronic stress during childhood associated with adult-onset vulvodynia? $J$ Womens Health (Larchmt). 2014;23(8):649-656.

37. AIPC Article Library October 27, 2015. Prevalence, incidence, and risk factors for ASD and PTSD. Available from: http://www.aipc.net. $\mathrm{au} /$ articles/prevalence-incidence-and-risk-factors-for-asd-and-ptsd/. Accessed March 21, 2017.

38. Moeller-Bertram T, Keltner J, Strigo IA. Pain and post traumatic stress disorder - review of clinical and experimental evidence. Neuropharmacology. 2012;62(2):586-597.

39. Pulvers K, Hood A. The role of positive traits and pain catastrophizing in pain perception. Curr Pain Headache Rep. 2013;17(5):330.

40. Moore E, Thibault P, Adams H, Sullivan MJL. Catastrophizing and painrelated fear predict failure to maintain treatment gains following participation in a pain rehabilitation program. Pain Reports. 2016;1(2):e567.

41. Burton E, Campbell C, Robinson M, Bounds S, Buenaver L, Smith M (322) Sleep mediates the relationship between central sensitization and clinical pain. J Pain. 2016;17(4S):S56.

42. Schuh-Hofer S, Wodarski R, Pfau DB, et al. One night of total sleep deprivation promotes a state of generalized hyperalgesia: a surrogate pain model to study the relationship of insomnia and pain. Pain. 2013;154(9) 1613-1621.

43. Nguyen RH, Ecklund AM, Maclehose RF, Veasley C, Harlow BL. Co-morbid pain conditions and feelings of invalidation and isolation among women with vulvodynia. Psychol Health Med. 2012;17(5):589-598.

44. Veasley C, Clare D, Clauw DJ, et al. Impact of chronic overlapping pain conditions on public health and the urgent need for safe and effective treatment: 2015 analysis and policy recommendations. Chronic Pain Research Alliance. 2015 White Paper. Available from: http://ChronicPainReasearch.org. Accessed June 1, 2017.

45. Reed BD, Sen A, Harlow SD, Haefner HK, Gracely RH. Multimodal vulvar and peripheral sensitivity among women with vulvodynia: a case-control study. J Low Genit Tract Dis. 2017;21(1):78-84.

46. Tommola P. Etiopathogenesis and Treatment of Localized Provoked Vulvodynia [doctoral dissertation]. Helsinki: University of Helsinki; 2017.

47. Farmer MA, Taylor AM, Bailey AL, et al. Repeated vulvovaginal fungal infections cause persistent pain in a mouse model of vulvodynia. Sci Transl Med. 2011;3(101):101ra91.

48. Gentilcore-Saulnier E, McLean L, Goldfinger C, Pukall CF, Chamberlain S. Pelvic floor muscle assessment outcomes in women with and without provoked vestibulodynia and the impact of a physical therapy program. J Sex Med. 2010;7(2 Pt 2):1003-1022.

49. van der Velde J, Laan E, Everaerd W. Vaginismus, a component of a general defensive reaction. An investigation of pelvic floor muscle activity during exposure to emotion-inducing film excerpts in women with and without vaginismus. Int Urogynecol J Pelvic Floor Dysfunct. 2001;12(5):328-331.

50. Hoffman D. Understanding multisymptom presentations in chronic pelvic pain: the inter-relationships between the viscera and myofascial pelvic floor dysfunction. Curr Pain Headache Rep. 2011;15(5):343-346.
51. Zolnoun D, Hartmann K, Lamvu G, As-Sanie S, Maixner W, Steege J. A conceptual model for the pathophysiology of vulvar vestibulitis syndrome. Obstet Gynecol Surv. 2006;61(6):395-401; quiz 423.

52. Giamberardino MA, Cervero F. The neural basis of referred visceral pain. In: Pasricha PJ, Willis WD, Gebhart GF, editors. Chronic Abdominal Visceral Pain. New York, NY: Informa Healthcare USA; 2007:178-203.

53. Greenstein A, Ben-Aroya Z, Fass O, et al. Vulvar vestibulitis syndrome and estrogen dose of oral contraceptive pills. J Sex Med. 2007; 4(6):1679-1683.

54. Reed BD, Harlow SD, Legocki LJ, et al. Oral contraceptive use and risk of vulvodynia: a population-based longitudinal study. BJOG. 2013;120(13):1678-1684.

55. Henzell H, Berzins K. Localised provoked vestibulodynia (vulvodynia): assessment and management. Aust Fam Physician. 2015;44(7): 460-466.

56. Van der Kolk B. The Body Keeps the Score. Mind, Brain and Body in the Transformation of Trauma. Penguin; UK. 2014.

57. Reed BD, Plegue MA, Harlow SD, Haefner HK, Sen A. Does degree of vulvar sensitivity predict vulvodynia characteristics and prognosis? J Pain. 2017;18(2):113-123.

58. DeAndres J, Sanchis-LopezN, Asensio-Samper JM, et al. Vulvodynia-an evidence-based literature review and proposed treatment algorithm. Pain Pract. 2016;16(2):204-236.

59. Brotto LA, Yong P, Smith KB, Sadownik LA. Impact of a multidisciplinary vulvodynia program on sexual functioning and dyspareunia. $J$ Sex Med. 2015;12(1):238-247.

60. Goldstein AT, Pukall CF, Brown C, Bergeron S, Stein A, KelloggSpadt S. Vulvodynia: assessment and treatment. J Sex Med. 2016;13(4): 572-590.

61. American College of Obstetricians and Gynecologists' Committee on Gynecologic Practice; American Society for Colposcopy and Cervical Pathology (ASCCP). Committee Opinion No. 673: persistent vulvar pain. Obstet Gynecol. 2016;128(3):e78-e84.

62. Di Biase M, Lacovelli V, Kocjancic E. Vulvodynia: current etiology, diagnosis, and treatment. Curr Bladder Dysfunct Rep. 2016;11(3): $248-257$.

63. Davis SN, Bergeron S, Binik YM, Lambert B. Women with provoked vestibulodynia experience clinically significant reductions in pain regardless of treatment: results from a 2-year follow-up study. $J$ Sex Med. 2013;10(12):3080-3087.

64. Workowski KA, Bolan GA; Centers for Disease Control and Prevention. Sexually transmitted diseases treatment guidelines, 2015. MMWR Recomm Rep. 2015;64(RR-03):1-137.

65. Louw A, Zimney K, Puentedura EJ, Diener I. The efficacy of pain neuroscience education on musculoskeletal pain: a systematic review of the literature. Physiother Theory Pract. 2016;32(5):332-355.

66. Brotto LA, Sadownik L, Thompson S. Impact of educational seminars on women with provoked vestibulodynia. J Obstet Gynaecol Can. 2010; 32(2):132-138.

67. Bystad M, Bystad C, Wynn R. How can placebo effects best be applied in clinical practice? A narrative review. Psychol Res Behav Manag. 2015;8:41-45

68. Kaptchuk TJ, Miller FG. Placebo effects in medicine. $N$ Engl J Med. 2015;378:8-9.

69. Carvalho C, Caetano JM, Cunha L, Rebouta P, Kaptchuk TJ, Kirsch I. Open-label placebo treatment in chronic low back pain: a randomized controlled trial. Pain. 2016;157(12):2766-2772.

70. Riess H. Empathy in medicine - a neurobiological perspective. JAMA. 2010;304(14):1604-1605

71. Manchikanti L, Giordano J, Fellows B, Hirsch JA. Placebo and nocebo in interventional pain management: a friend or a foe - or simply foes? Pain Physician. 2011;14(2):E157-E175.

72. Goetsch MF, Lim JY, Caughey AB. A practical solution for dyspareunia in breast cancer survivors: a randomized controlled trial. J Clin Oncol. 2015;33(30):3394-3400.

73. Rosenbaum TY, Owens A. The role of pelvic floor physical therapy in the treatment of pelvic and genital pain-related sexual dysfunction (CME). J Sex Med. 2008;5(3):513-523; quiz 524-525. 
74. Goldfinger C, Pukall CF, Gentilcore-Saulnier E, McLean L, Chamberlain S. A prospective study of pelvic floor physical therapy: pain and psychosexual outcomes in provoked vestibulodynia. $J$ Sex Med. 2009;6(7):1955-1968.

75. Oyama IA, Rejba A, Lukban JC, et al. Modified Thiele massage as therapeutic intervention for females with interstitial cystitis and hightone pelvic floor dysfunction. Urology. 2004;64(5):862-865.

76. Nijs J, Lluch Girbés E, Lundberg M, Malfliet A, Sterling M. Exercise therapy for chronic musculoskeletal pain: innovation by altering pain memories. Man Ther. 2015;20(1):216-220.

77. Masheb RM, Kerns RD, Lozano C, Minkin MJ, Richman S. A randomized clinical trial for women with vulvodynia: cognitive-behavioural therapy vs. supportive psychotherapy. Pain. 2009;141(1-2):31-40.

78. Strigo IA, Simmons AN, Matthews SC, Craig AD. The relationship between amygdala activation and passive exposure time to an aversive cue during a continuous performance task. PLoS One. 2010;5(11): e15093.

79. Basson R. The recurrent pain and sexual sequelae of provoked vestibulodynia: a perpetuating cycle. J Sex Med. 2012;9(8):2077-2092.

80. Pâquet M, Bois K, Rosen NO, Mayrand MH, Charbonneau-Lefebvre V, Bergeron S. Why us? Perceived injustice is associated with more sexual and psychological distress in couples coping with genito-pelvic pain. J Sex Med. 2016;13(1):79-87.

81. Boerner KE, Rosen NO. Acceptance of vulvovaginal pain in women with provoked vestibulodynia and their partners: associations with pain, psychological, and sexual adjustment. J Sex Med. 2015;12(6):1450-1462.

82. Sadownik LA. Etiology, diagnosis, and clinical management of vulvodynia. Int $J$ Womens Health. 2014;6:437-449.

83. Smith KB, Pukall CF. A systematic review of relationship adjustment and sexual satisfaction among women with provoked vestibulodynia. J Sex Res. 2011;48(2-3):166-191.

84. Bergeron S, Binik YM, Khalifé S, et al. A randomized comparison of group cognitive - behavioral therapy, surface electromyographic biofeedback, and vestibulectomy in the treatment of dyspareunia resulting from vulvar vestibulitis. Pain. 2001;91(3):297-306.

85. Piper CK, Legocki LJ, Moravek MB, et al. Experience of symptoms, sexual function, and attitudes toward counseling of women newly diagnosed with vulvodynia. J Low Genit Tract Dis. 2012;16(4): 447-453.

86. Spoelstra SK, Borg C, Weijmar Schultz WC. Anticonvulsant pharmacotherapy for generalized and localized vulvodynia: a critical review of the literature. J Psychosom Obstet Gynaecol. 2013;34(3): 133-138.

87. Finnerup NB, Attal N, Haroutounian S, et al. Pharmacotherapy for neuropathic pain in adults: a systematic review and meta-analysis. Lancet Neurol. 2015;14(2):162-173.
88. Moulin D, Boulanger A, Clark AJ, et al; Canadian Pain Society. Pharmacological management of chronic neuropathic pain: revised consensus statement from the Canadian Pain Society. Pain Res Manag. 2014;19(6):328-335.

89. Tommola P, Unkila-Kallio L, Paavonen J. Long-term well-being after surgical or conservative treatment of severe vulvar vestibulitis. Acta Obstet Gynecol Scand. 2012;91(9):1086-1093.

90. Glazer HI, Rodke G, Swencionis C, Hertz R, Young AW. Treatment of vulvar vestibulitis syndrome with electromyographic biofeedback of pelvic floor musculature. J Reprod Med. 1995;40(4):283-290.

91. Danielsson I, Torstensson T, Brodda-Jansen G, Bohm-Starke N. EMG biofeedback versus topical lidocaine gel: a randomized study for the treatment of women with vulvar vestibulitis. Acta Obstet Gynecol Scand. 2006;85(11):1360-1367.

92. Murina F, Bernorio R, Palmiotto R. The use of amielle vaginal trainers as adjuvant in the treatment of vestibulodynia: an observational multicentric study. Medscape J Med. 2008;10(1):23.

93. Rosenbaum TY. Physiotherapy treatment of sexual pain disorders. $J$ Sex Marital Ther. 2005;31(4):329-340.

94. Vlaeyen JWS, Morley SJ, Linton SJ, Boersma K, de Jong J. PainRelated Fear: Exposure-Based Treatment of Chronic Pain. Seattle, WA: IASP Press; 2012:196.

95. Murina F, Bianco V, Radici G, Felice R, Di Martino M, Nicolini U. Transcutaneous electrical nerve stimulation to treat vestibulodynia: a randomised controlled trial. BJOG. 2008;115(9):1165-1170.

96. Vallinga MS, Spoelstra SK, Hemel IL, van de Wiel HB, Weijmar Schultz WC. Transcutaneous electrical nerve stimulation as an additional treatment for women suffering from therapy-resistant provoked vestibulodynia: a feasibility study. J Sex Med. 2015;12(1): 228-237.

97. Schlaeger JM, Xu N, Mejta CL, Park CG, Wilkie DJ. Acupuncture for the treatment of vulvodynia: a randomized wait-list controlled pilot study. J Sex Med. 2015;12(4):1019-1027.

98. Curran S, Brotto LA, Fisher H, Knudson G, Cohen T. The ACTIV study: acupuncture treatment in provoked vestibulodynia. J Sex Med. 2010;7(2 Pt 2):981-995.

99. Ogden P, Fisher J. Sensorimotor Psychotherapy: Interventions for Trauma and Attachment. New York, NY: Norton; 2014.

100. Morrissey D, El-Khawand D, Ginzburg N, Wehbe S, O’Hare P 3rd, Whitmore K. Botulinum Toxin A injections into pelvic floor muscles under electromyographic guidance for women with refractory hightone pelvic floor dysfunction: a 6 month prospective pilot study. Female Pelvic Med Reconstr Surg. 2015;21(5):277-282.
International Journal of Women's Health

\section{Publish your work in this journal}

The International Journal of Women's Health is an international, peerreviewed open-access journal publishing original research, reports, editorials, reviews and commentaries on all aspects of women's healthcare including gynecology, obstetrics, and breast cancer. The manuscript management system is completely online and includes

\section{Dovepress}

a very quick and fair peer-review system, which is all easy to use Visit http://www.dovepress.com/testimonials.php to read real quotes from published authors. 